\title{
The use of ultrasonic detectors for water stress determination in fruit trees
}

\author{
H.G. Jones ${ }^{1}$, K.H. Higgs ${ }^{2}$ and A. Bergamini ${ }^{3}$ \\ 1 Institute of Horticultural Research, Wellesbourne, Warwick, U.K., \\ 2 Institute of Horticultural Research, East Malling, Maidstone, U.K., and \\ 3 Istituto Sperimentale per la Frutticoltura, Trento, Italy
}

\section{Introduction}

In drought, the hydraulic conductance in tree stems can be reduced by embolisms that occur within xylem vessels and tracheids. There is good circumstantial evidence that these cavitation events can be detected acoustically, either at low frequency, i.e., $0.2-2 \mathrm{kHz}$ (Milburn and Johnson, 1966) or high frequency, i.e., 0.1-1.0 $\mathrm{MHz}$ (Tyree and Dixon, 1983) It is important to know at what stage cavitations occur and whether there are inherent differences between varieties or species. As a tool to investigate cavitation events, we have used ultrasound detectors, since they are able to operate in a noisy environment or in field conditions without background interference.

\section{Materials and Methods}

Using a circuit design based on that by Sandford and Grace (1984), acoustic emissions (AE) were converted into $5 \mathrm{~V}$ pulses and recorded on a counter or logger. AE production of 3 apple cultivars (Cox's Orange Pippin, Golden Delicious and A120/3) on 2 rootstocks (M.9 and $M .25$ ) were compared in a glasshouse drought experiment from 8-10 October 1987. 24 potted trees were transferred from a sandbed on 4 October and water was withheld from 2 of each rootstock/cultivar combination. Three days later, water was withheld from one more tree from each combination, the remainder of the trees being retained as well-watered controls. Two ultrasound transducers were attached to stems of pairs of trees to record counts over $5 \mathrm{~min}$ periods. Each transducer was mounted onto the xylem tissue of the rootstock stem (covered with petroleum jelly) about $10 \mathrm{~cm}$ below the graft union. Leaf water potential ( $\psi_{1}$, down to -4 $\mathrm{MPa}$ ) and conductance to water vapor $\left(g_{1}\right)$ were monitored concurrently with $A E$.

\section{Results}

Results are presented for the 3 cultivars separately in Fig. 1. There was a clear rootstock effect with the count rate for M.9 being up to 6 times that for M.25, depending upon $\psi_{1}$. The threshold of $\psi_{1}$ at 

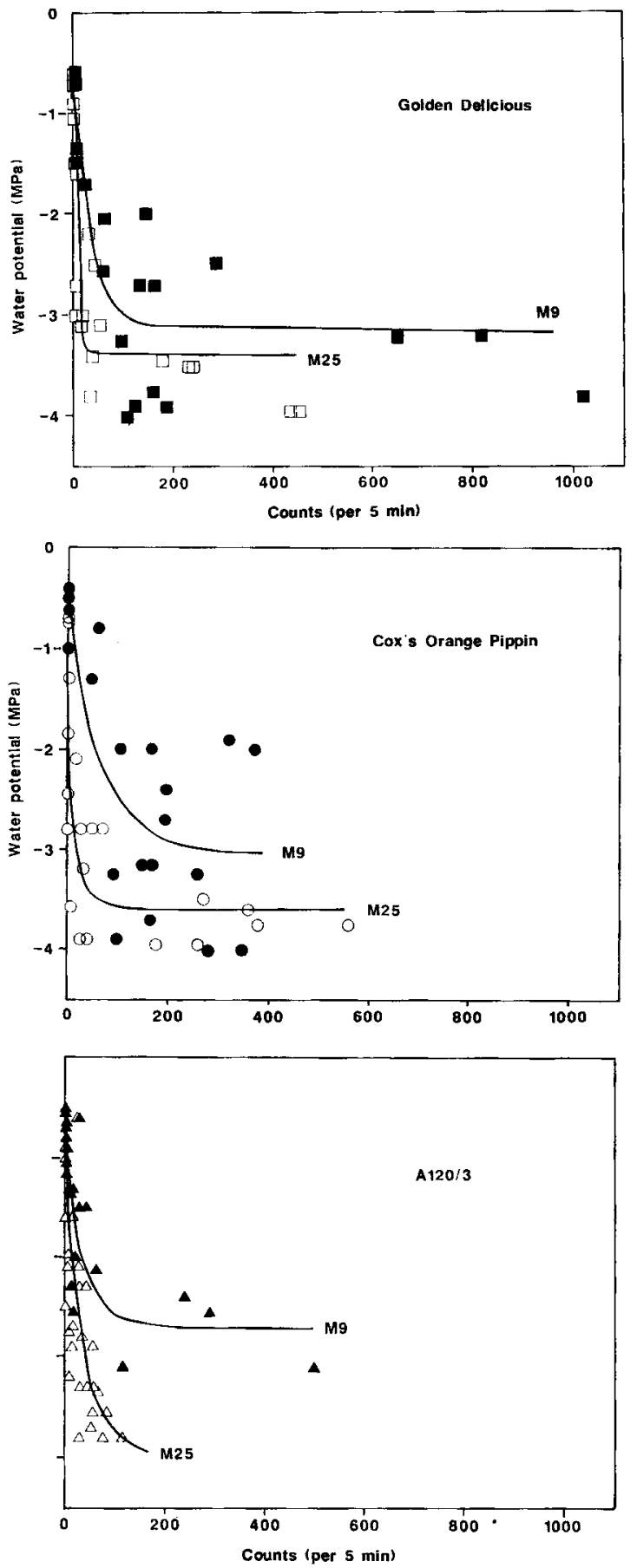

Fig. 1. AE from dwarfing (M.9) and vigorous (M.25) rootstocks for three apple cultivars during a drought course. 
Table I. Threshold values of $\psi_{1}$ (MPa), above which few AE were observed.

\begin{tabular}{llll}
\hline & Cox & $\begin{array}{l}\text { Golden } \\
\text { Delicious }\end{array}$ & A120/3 \\
\hline M.9 & -0.6 & -0.7 & -0.6 \\
M.25 & -1.7 & -1.2 & -1.0 \\
\hline
\end{tabular}

which AEs started was different for the various rootstock/cultivar combinations (Table I).

The cultivar effect was not so marked, although there was a tendency for fewer AE to be produced at any $\psi_{1}$ for $A 120 / 3$ on M.25 when compared with the other cultivars on the same rootstock. On no occasion did $A E$ for well-watered controls exceed 2 per $5 \mathrm{~min}$ and were usually zero. There was some evidence with individual plants that $A E$ decreased after prolonged stress.

In a separate experiment, $A E$ were monitored diurnally (along with radiation) using a data logger recording at $30 \mathrm{~min}$ intervals. Two trees were used: $A 120 / 3$ on M.25 and Cox on M.9. The pattern of $\psi_{1}$ vs AE was similar to that in the previous experiment. It was evident from the time courses that a marked diurnal pattern existed where AE followed radiation (PAR) levels approximately, except in some instances when AE increased, or continued, during the night (Fig. 2).

\section{Discussion and Conclusion}

These results indicate that the response to applied drought in apple trees produced more $A E$ ir a dwarfing rootstock (M.9) than in a vigorous one (M.25) for a given $\psi_{1}$. Also there was a threshold of $\psi_{1}$, below which $\mathrm{AE}$ start to occur. This was different for the 2 rootstocks. Other evidence suggests that embolised vessels are not easily refilled (Milburn, 1979;

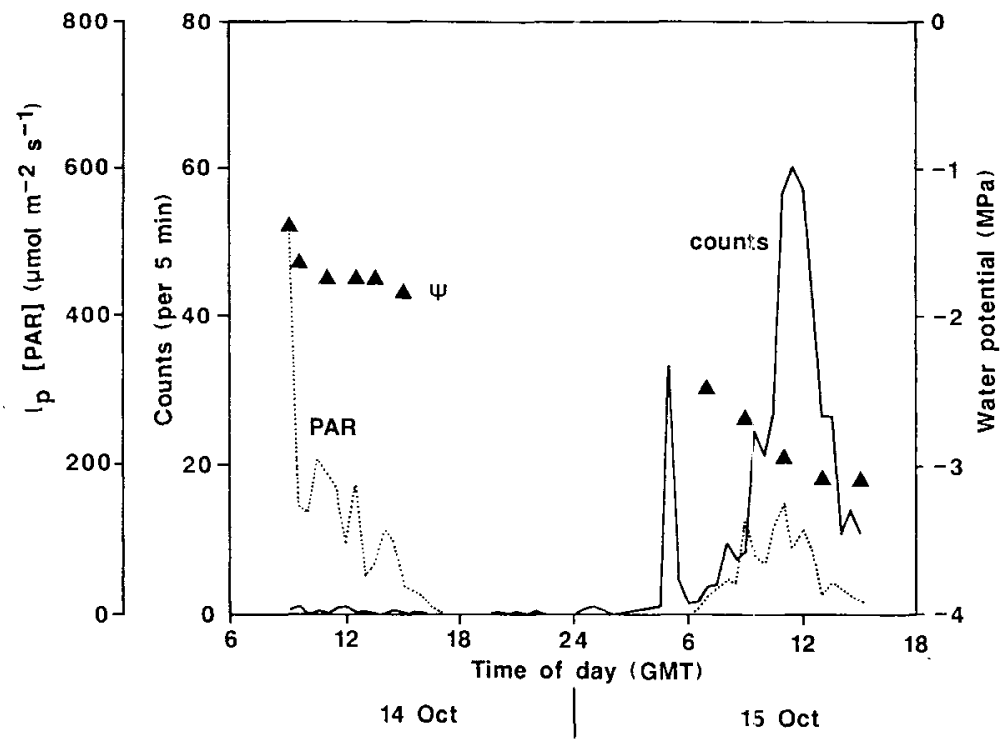

Fig. 2. Diurnal course of AE for A120/3 on M.25 rootstock. 
Jones and Peña, 1986) and so a cumulative reduction in hydraulic conductivity could occur. Work is continuing in order to evaluate the technique for assessing plant responses to drought in the field and as a means of measuring physiological water stress.

\section{References}

Jones H.G. \& Peña J. (1986) Relationships between water stress and ultrasound emission in apple (Malus $\times$ domestica Borkh.). J. Exp. Bot. 37, 1245-1254

Milburn J.A. (1979) In: Water Flow in Plants. Longman, London

Milburn J.A. \& Johnson R.P.C. (1966) The conduction of sap. II. Detection of vibrations produced by sap cavitations in Ricinus stem. Planta 69, 43-52

Sandford A.P. \& Grace J. (1985) The measurement and interpretation of ultrasound from woody stems. J. Exp. Bot. 36, 298-311

Tyree M.T. \& Dixon M.A. (1983) Cavitation events in Thuja occidentalis L.? Ultrasonic acoustic emissions from the sapwood can be measured. Plant Physiol. 72, 1094-1099 